\title{
Suku Phyllanthaceae pada Rawa Bakau dan Tambak di Telang Asri, Kabupaten Bangkalan, Pulau Madura
}

\section{Phyllanthaceae of Mangrove Swamp and Fishpond in Telang Asri, Bangkalan Regency, Madura Island}

\author{
ARIFIN SURYA DWIPA IRSYAM ${ }^{*}$, MUHAMMAD RIFQI HARIRI ${ }^{2}$, RINA RATNASIH IRWANTO ${ }^{3}$, ASHARI \\ BAGUS SETIAWAN ${ }^{4}$ \\ ${ }^{1}$ Herbarium Bandungense (FIPIA), Sekolah Ilmu dan Teknologi Hayati, Institut Teknologi Bandung, Sumedang, \\ Indonesia \\ ${ }^{2}$ Pusat Penelitian Konservasi Tumbuhan dan Kebun Raya, Lembaga Ilmu Pengetahuan Indonesia, Bogor, Indonesia \\ ${ }^{3}$ Sekolah Ilmu dan Teknologi Hayati, Institut Teknologi Bandung, Bandung, Indonesia \\ ${ }^{4}$ UPT. Laboratorium Terpadu, Universitas Trunojoyo Madura, Madura, Indonesia
}

Diterima 5 Maret 2020/Disetujui 23 September 2020

\begin{abstract}
Madura island is known as a mixed deciduous forest area with dry seasons and limestone soil. The island has unique plant species compared to the mainland Java. However, most of the mangrove forest areas have been converted into ponds and housing. One of the remaining mangrove swamps is located at Telang Asri village, Kamal Subdistrict, Bangkalan Regency. Several species of mangroves have been reported here, along with other groups of plants from the Phyllanthaceae family, found numerously at the time of observation. In 1963, CA Backer and RC Bakhuizen van den Brink Jr. have already listed 16 species of Phyllanthaceae from Madura Island. Since then, the updated information on the Phyllanthaceae of Madura has not been available. Therefore, this study aimed to collect the members of Phyllanthaceae family in the mangrove swamp areas of Telang Asri village. The field study was carried out using the exploratory method, while specimen preparation was conducted in Herbarium Bandungense (FIPIA). In this study, seven species were collected from Telang Asri, namely Glochidion littorale Blume, G. zeylanicum (Gaertn.) A. Juss., Phyllanthus amarus Schumach. and Thonn., P. debilis Klein ex Willd., P. reticulatus Poir., P. urinaria L., and P. virgatus G. Forst.
\end{abstract}

Key words: Bangkalan, Kamal, Madura, Phyllanthaceae, Glochidion, Phyllanthus

\section{PENDAHULUAN}

Pulau Madura merupakan kawasan hutan gugur campuran yang beriklim kering dan bertanah kapur. Faktor lingkungan tersebut menyebabkan jenisjenis tumbuhan di pulau tersebut menjadi khas dan unik (Rifai 2013a). Meskipun begitu, lahan di Madura telah mengalami alih fungsi secara besarbesaran sejak pertengahan abad ke dua puluh. Hal tersebut mengakibatkan sebagian besar vegetasi alaminya berubah menjadi kawasan permukiman dan pertambangan kapur (Rifai 2013a; Irsyam 2015). Saat ini sisa vegetasi alami di Pulau Madura hanya terdapat di daerah aliran sungai, tempat-tempat yang dikeramatkan, Hutan Kera Nipah, dan daerah-daerah yang tidak bertuan (Rifai 2013b).

Kabupaten Bangkalan masih tercatat memiliki beberapa kawasan hutan bakau, seperti Desa Martajasah dan Desa Tengket (Supriyadi et al. 2015; Amalia et

*Penulis korespondensi:

E-mail: arifin@sith.itb.ac.id al. 2016). Akan tetapi, pada tahun 2013, Kabupaten Bangkalan telah kehilangan hutan bakau seluas 38.06 hektar, akibat penebangan liar dan konversi lahan menjadi tambak serta permukiman (Hidayah dan Suharyo 2018). Permasalahan ekonomi dan demografi merupakan faktor pendorong terjadinya alih fungsi lahan di daerah pesisir Selat Madura. Lahan bakau dianggap sebagai lahan yang kurang produktif dan tidak dapat memberikan manfaat secara maksimal bagi masyarakat sekitar (Hidayah dan Suharyo 2018).

Salah satu kawasan rawa bakau yang tersisa di Kecamatan Kamal terdapat di Dusun Telang Asri, Desa Telang. Akan tetapi, saat ini sebagian besar lahan bakaunya telah ditimbun dengan batu kapur untuk dijadikan kawasan permukiman. Penelitian terdahulu menunjukkan bahwa jenis-jenis tumbuhan bakau sejati, seperti Acanthus ilicifolius L. (Acanthaceae), Acrostichum aureum L. (Pteridaceae), Rhizophora sp. (Rhizophoraceae), Sonneratia alba Sm. (Lythraceae), masih dapat ditemukan di Telang Asri (Setiawan 2016). Sementara itu, tumbuhan bakau ikutan yang tumbuh di lokasi tersebut antara lain Ardisia elliptica Thunb. 
(Primulaceae), Calotropis gigantea (L.) Dryand. (Apocynaceae), Flagellaria indica L.(Flagellariaceae), Melanthera biflora (L.) Wild (Asteraceae), Morinda citrifolia L. (Rubiaceae), Passiflora foetida L. (Passifloraceae), dan Typha angustifolia L. (Typhaceae) (Setiawan 2016). Selain tumbuhan bakau sejati dan bakau ikutan, beberapa jenis tumbuhan dari suku Phyllanthaceae juga tumbuh di Telang Asri.

Suku Phyllanthaceae yang terdapat di Pulau Madura hanya diwakili oleh 6 marga, yaitu Antidesma (2 jenis), Glochidion (4 jenis), Breynia (1 jenis), Phyllanthus (7 jenis), Synostemon (1 jenis), dan Sauropus (1 jenis) (Backer dan Bakhuizen v/d Brink 1963). Sejak Flora of Java jilid pertama terbit pada tahun 1963, informasi terkini mengenai Phyllanthaceae di Madura belum tersedia. Hal tersebut dikarenakan penelitian botani di Madura masih sedikit dan komposisi floranya masih dianggap sama dengan Pulau Jawa, sehingga informasi Flora Madura belum tersusun secara lengkap (Irsyam 2015). Selain itu, anggota suku Phyllanthaceae yang tumbuh di sekitar kawasan bakau juga tidak disebutkan secara jelas dalam catatan Backer. Dengan demikian, penelitian ini bertujuan untuk menginventarisasi anggota suku Phyllanthaceae pada rawa bakau dan tambak di Dusun Telang Asri. Penelitian ini juga dilakukan sebagai bagian dari penulisan Phyllanthaceae Madura.

\section{BAHAN DAN METODE}

Penelitian ini merupakan bagian dari ekspedisi Flora Madura yang dilakukan di Kabupaten Bangkalan, Sampang, Pamekasan, dan Sumenep, pada bulan Desember 2019. Inventarisasi jenis-jenis tumbuhan dari suku Phyllanthaceae yang tumbuh pada ekosistem rawa bakau dan tambak dilakukan di Dusun Telang Asri, Desa Telang, Kecamatan Kamal, Bangkalan. Eksplorasi lapangan dilakukan menggunakan metode jelajah mengikuti Rugayah et al. (2004) dan pengambilan spesimen mengikuti metode van Balgooy (1987). Bagian tumbuhan yang diambil berupa satu ranting yang lengkap dengan organ vegetatif dan generatifnya. Data-data lapangan, seperti nama kolektor, nomor koleksi, lokasi pengambilan, nama lokal, manfaat, dan ciri morfologi setiap jenis, juga dicatat selama pengamatan berlangsung. Selanjutnya, spesimen dari lapangan diproses menjadi awetan kering di Herbarium Bandungense (FIPIA), Sekolah Ilmu dan Teknologi Hayati (SITH), Institut Teknologi Bandung (ITB). Pengamatan spesimen juga dilakukan di Herbarium Universitas Trunjoyo Madura (UTM) pada bulan Desember 2019.

Proses identifikasi dalam penelitian ini menggunakan $A$ revision of Phyllanthus (Euphorbiaceae) in The Continental United States (Webster 1970), A taxonomic revision of Phyllanthus subgenus Macraea
(Phyllanthaceae) (Verwijs et al. 2019), Flora of Java Vol. 1 (Backer dan Bakhuizen v/d Brink 1963), Flora of Thailand vol. 8 (2): Euphorbiaceae (Genera G-Z) (van Welzen dan Chayamarit 2007), Notes on Malesian and Other Asiatic Euphorbiaceae (Airy Shaw 1978), The Euphorbiaceae of Sumatra (Airy Shaw 1981), dan The Euphorbiaceae of Central Malesia (Celebes, Moluccas, Lesser Sunda Is.) (Airy Shaw 1982).

\section{HASIL}

Pada penelitian ini, sebanyak 7 jenis anggota suku Phyllanthaceae telah dikoleksi dari Telang Asri, yaitu Glochidion littorale Blume, G. zeylanicum (Gaertn.) A. Juss., Phyllanthus amarus Schumach. dan Thonn., $P$. debilis Klein ex Willd., P. reticulatus Poir., P. urinaria L., dan P. virgatus G. Forst. Marga Phyllanthus L. memiliki keanekaragaman jenis tertinggi, karena terdiri atas 5 jenis, sementara marga Glochidion JR. Forst dan $\mathrm{G}$ Forst hanya diwakili oleh 2 jenis.

Kunci identifikasi untuk anggota suku Phyllanthaceae di Telang Asri disajikan sebagai berikut.

Kunci Determinasi untuk Suku Phyllanthaceae di Telang Asri. (1) A: Panjang daun dewasa $\geq 3 \mathrm{~cm}$, bagian bunga tidak memiliki cakram bunga.............................2; $B$ : Panjang daun dewasa $<3 \mathrm{~cm}$, bagian bunga memiliki cakram bunga.................................... 3; (2) A: Helaian daun membundar atau membundar telur sungsang, ujung daun bergubang atau membundar, rusuk daun 7 pasang, bakal buah berlokul 10-14.

Glochidion littorale; B: Helaian daun melonjong, ujung daun melancip, rusuk daun 11-12 pasang, bakal buah berlokul 6 .

Glochidion zeylanicum; (3) A: Perdu, benang sari berjumlah 5 helai pada bunga jantan, buah berdaging saat masak. Phyllanthus

reticulatus; B: Terna, benang sari berjumlah 3 helai pada bunga jantan, buah kering.......................................4; (4) A: Cabang lateral berupa cabang phyllanthoid yang terlihat seperti daun majemuk, daun pada bagian batang utama tereduksi menjadi sisik, seluruh bagian tangkai sari saling berlekatan membentuk tabung....................5; B: Tanpa cabang phyllanthoid, semua daun berkembang sempurna, tangkai sari saling berlepasan....................Phyllanthus virgatus; (5) A: Batang hijau atau kemerahan, permukaan adaksial daun hijau gelap dengan tepi daun berwarna merah, permukaan buah berkutil.......................Phyllanthus urinaria; B: Batang hijau, permukaan adaksial daun hijau pucat, permukaan buah halus..........................6; (6) A: Cabang phyllanthoid zig-zag, pangkal daun membaji...............................Phyllanthus debilis; B: Cabang phyllanthoid lurus, pangkal daun membundarmenumpul............Phyllanthus amarus. 


\section{PEMBAHASAN}

Suku Phyllanthaceae terdistribusi secara kosmopolitan di dunia, terutama di kawasan tropis, dan terdiri lebih dari 1,200 jenis yang termasuk ke dalam 58 marga (Challen 2015). Pada sistem klasifikasi klasik, seluruh anggota suku Phyllanthaceae dianggap sebagai bagian dari Euphorbiaceae, karena keduanya memiliki bakal buah berlokul 3 (Backer dan Bakhuizen v/d Brink 1963). Meskipun demikian, kedua suku tersebut memiliki ciri morfologi pembeda yang khas antara satu dengan yang lain. Suku Phyllanthaceae tidak mengandung lateks, bagian daun tanpa kelenjar ekstrafloral, dan pada setiap lokul bakal buahnya terdapat dua buah bakal biji (Challen 2015). Selain itu, suku Phyllanthaceae memiliki buah bertipe skizokarp, pelok, buni, atau samara, sementara tipe buah pada suku Euphorbiaceae berupa kapsul (Challen 2015). Keduanya kemudian dipisahkan menjadi dua suku berbeda dalam sistem klasifikasi terbaru APG IV yang berbasis kajian filogenetik (APG 2016).

Suku Phyllanthaceae merupakan salah satu kelompok tumbuhan yang mampu tumbuh pada lahan rawa bakau dan tambak yang telah mengalami alih fungsi lahan di Dusun Telang Asri. Hal tersebut dikarenakan sebagian besar jenis tumbuhan dari suku tersebut merupakan tumbuhan pionir pada habitat yang rusak dan terbuka (Chia et al. 2017). Selain itu, beberapa jenis tumbuhan dari suku Phyllanthaceae juga memiliki adaptasi untuk hidup pada eksosistem hutan bakau (Giesen et al. 2006; Tomlinson 2016; Heijkoop dan van Welzen 2017). Kondisi rawa bakau dan tambak yang diamati dalam penelitian ini ditunjukkan pada Gambar 1. Suku Phyllanthaceae yang telah dikoleksi dari Telang Asri terdiri dari 7 jenis dan tercakup ke dalam 2 marga, yakni Glochidion dan Phyllanthus (Gambar 2).

Berdasarkan catatan Backer dalam Flora of Java, Glochidion yang tumbuh di Pulau Madura antara lain $G$. littorale Blume, $G$. molle Blume, $G$. obscurum (Willd.) Blume, dan G. rubrum Blume (Backer dan Bakhuizen v/d Brink 1963). Pada penelitian ini, Glochidion yang dikoleksi dari Telang Asri hanya terdiri dari 2 jenis, yaitu G. littorale dan G. zeylanicum. Pada umumnya G. littorale tumbuh pada daerah dekat pantai atau vegetasi bakau dan dikelompokkan sebagai jenis bakau ikutan (Giesen et al. 2006; Yuliana et al. 2019). Secara tradisional, masyarakat di sekitar lahan rawa memakan buah G. littorale sebagai buah segar, karena seludang bijinya memiliki rasa yang manis saat masak. Sementara itu, keberadaan G. zeylanicum di Madura belum pernah dilaporkan sebelumnya oleh peneliti terdahulu, sehingga jenis ini ditetapkan sebagai sebuah rekaman baru untuk informasi Flora Madura. Dengan demikian, penemuan ini dapat menambah jumlah jenis Glochidion yang ada di Madura.

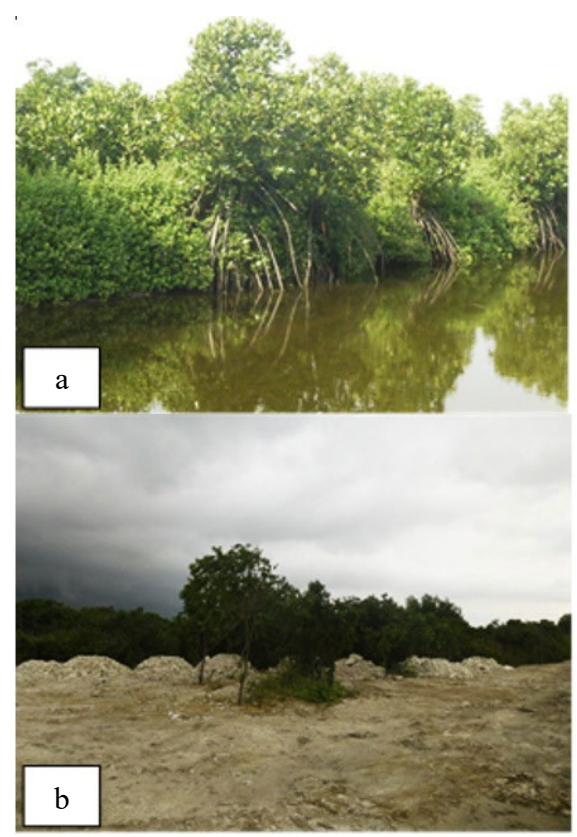

Gambar 1. Kawasan rawa bakau dan tambak di Telang Asri, Kecamatan Kamal, Bangkalan. (a) Rawa bakau yang dimanfaatkan sebagai tambak, (b). lahan rawa bakau yang telah ditimbun oleh tanah dan batu kapur
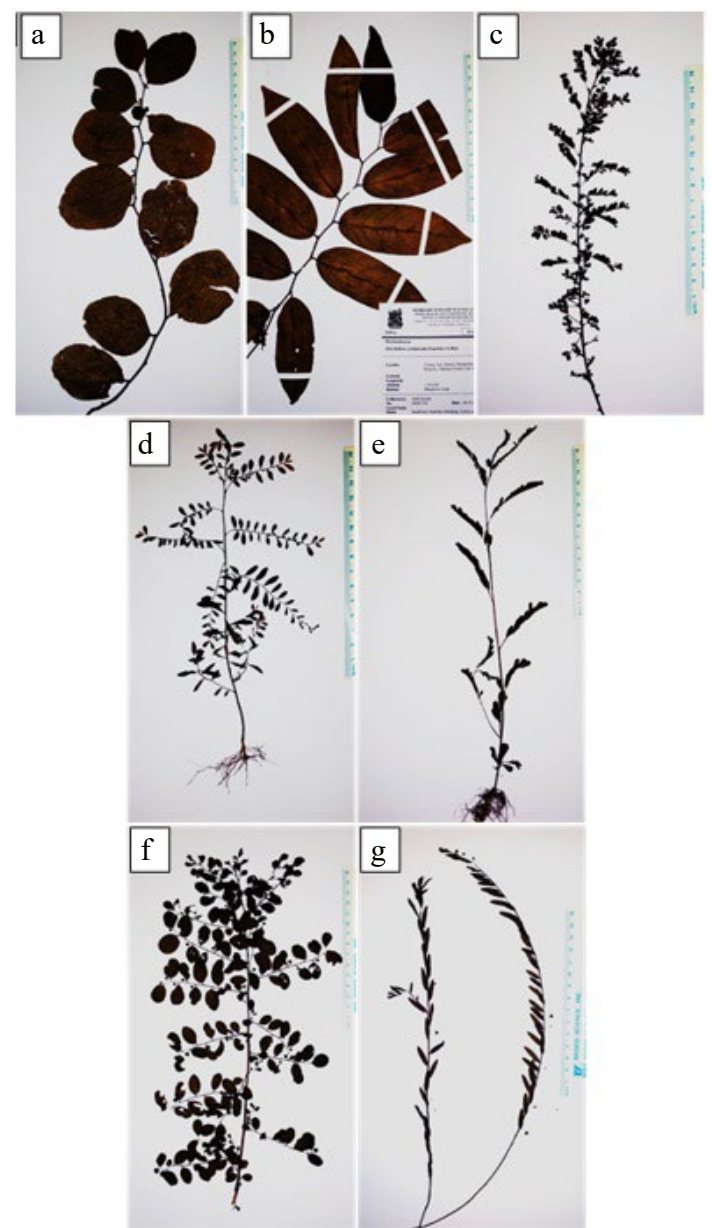

Gambar 2. Jenis-jenis tumbuhan dari suku Phyllanthaceae pada ekosistem rawa bakau dan tambak di Telang Asri, Bangkalan. (a) Glochidion littorale, (b). G. zeylanicum, (c). Phyllanthus amarus, (d).P. debilis, (e) P. urinaria, (f) P. reticulatus, (g) P. virgatus 
Jenis-jenis Phyllanthus yang dikoleksi dari Telang Asri dibagi menjadi 2 kelompok berdasarkan tipe percabangannya. Kelompok 1 mencakup jenisjenis yang memiliki cabang Phyllanthoid, yaitu $P$. amarus, $P$. debilis, $P$. reticulatus, dan $P$. urinaria. Kelompok 2 hanya diwakili oleh $P$. virgatus karena jenis ini tidak memiliki cabang phyllanthoid. Cabang phyllanthoid merupakan sebuah tipe percabangan yang khas pada marga Phyllanthus dan terlihat seperti sebuah daun majemuk menyirip (Gambar 3). Dimorfisme daun ditemukan pada jenis yang memiliki cabang phyllanthoid. Daun di bagian batang utama termodifikasi menjadi sisik, sedangkan daun yang berkembang normal hanya terdapat pada cabang phyllanthoid saja (Webster 1970).

Pengelompokkan Phyllanthus di Telang Asri sejalan dengan posisinya secara taksonomi. Phyllanthus virgatus merupakan anggota dari anak marga Macraea (Wight) Jean F. Brunel, di mana anak marga tersebut dicirikan dengan tidak adanya cabang phyllanthoid (Bouman et al. 2018b; Verwijs et al. 2019). Keempat jenis lainnya, yakni $P$. amarus, $P$. debilis, $P$. reticulatus, dan $P$. urinaria, masing-masing secara berurutan dikelompokkan ke dalam anak marga Swartziani (G. L. Webster) Ralim. dan Petra Hoffm., Afroswartziani Ralim. dan Petra Hoffm., Kirganelia (A. Juss.) Kurz, dan Phyllanthus (Bouman et al. 2018b). Adanya cabang phyllanthoid merupakan ciri penyatu dari ke empat anak marga tersebut. Dengan demikian, tipe percabangan dapat digunakan sebagai ciri pembeda Phyllanthus pada tingkat anak marga.

Penimbunan lahan rawa maupun tambak dengan tanah dan batu kapur di Telang Asri (Gambar 1b) telah menjadikan lokasi tersebut kering dan mampu ditumbuhi jenis-jenis Phyllanthus. Sebagian besar jenis yang dikoleksi dari Telang Asri, yaitu Phyllanthus amarus, P. debilis, dan P. urinaria, merupakan tumbuhan gulma yang umumnya dijumpai di daerah perkebunan (Soerjani et al. 1987; Souleymane et al. 2018; Hariri dan Irsyam 2019). Rawa bakau dan tambak di Telang Asri dikelilingi oleh permukiman dan kebun masyarakat. Oleh sebab itu, $P$. amarus, $P$. debilis, dan $P$. urinaria yang tumbuh pada lokasi tersebut diduga berasal dari lahan perkebunan di sekitarnya.

Biji Phyllanthus juga dapat mengontaminasi batu kapur dan tanah yang digunakan untuk menimbun lahan rawa serta tambak. Oleh sebab itu, ketiganya dapat tumbuh di lahan-lahan rawa dan tambak yang telah kering. Ketiga jenis tersebut juga memiliki biji yang berukuran sangat kecil, sehingga bijinya dapat disebarkan secara tidak sengaja oleh manusia atau hewan (Webster 1970). Dua jenis sisanya, yakni $P$. reticulatus dan $P$. virgatus, merupakan jenis tumbuhan yang umum ditemukan pada daerah dataran rendah yang kering di Pulau Madura (Backer dan Bakhuizen v/d Brink 1963).

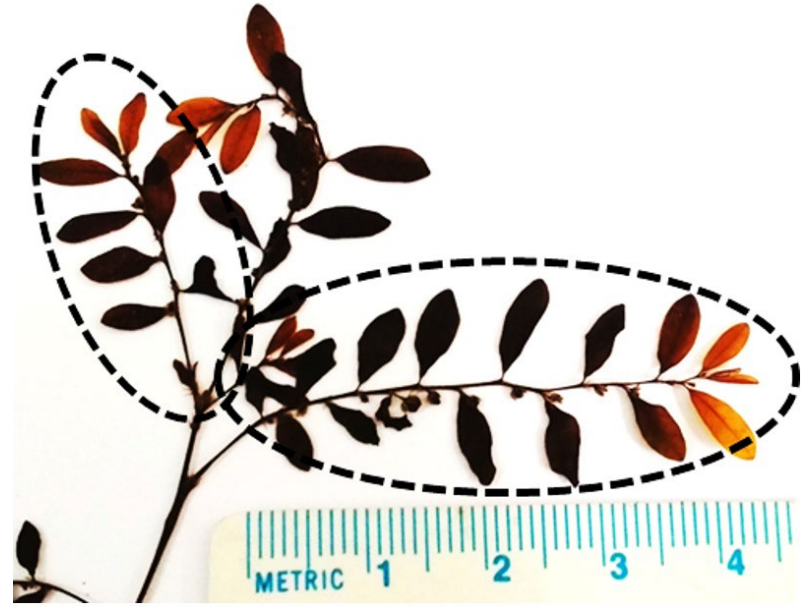

Gambar 3. Cabang phyllanthoid (garis putus-putus) pada $P$. debilis yang menyerupai sebuah daun majemuk menyirip

Hal tersebut menyebabkan keduanya memiliki kemampuan adaptasi untuk tumbuh di lahan-lahan rawa bakau yang telah dikeringkan.

Sebanyak 7 jenis Phyllanthus yang tersebar di Pulau Madura telah dicatat sebelumnya oleh Backer pada tahun 1963, yaitu P. emblica L., P. niruri L., $P$. urinaria L., P. reticulatus Poir., P. virgatus G. Forst., dan P. zollingeri Müll.Arg. (Backer dan Bakhuizen v/d Brink 1963). Pada penelitian ini, didapatkan 2 jenis yang belum tercatat sebelumnya, yaitu $P$. amarus dan $P$. debilis. Kedua jenis tersebut belum tercatat dalam Flora of Java, namun telah terekam ada di Pulau Jawa berdasarkan data The Global Biodiversity Information Facility (Backer dan Bakhuizen v/d Brink 1963; GBIF 2019a; GBIF 2019b). Akan tetapi, informasi mengenai sebaran keduanya belum pernah tercatat di Pulau Madura, baik oleh Backer maupun data GBIF. Oleh karena itu, $P$. amarus dan P. debilis dapat dikategorikan sebagai rekaman baru untuk Flora Madura. Phyllanthus amarus berasal dari Meksiko Selatan dan Amerika Tropis serta telah terintroduksi ke Alabama hingga Australia Barat (GBIF 2019a). Phyllanthus debilis tersebar dari Maladewa hingga Malesia Barat dan telah terintroduksi dari Bangladesh hingga Pulau Windward (GBIF 2019b).

Penelitian terdahulu menunjukkan bahwa Phyllanthaceae memiliki kemampuan untuk menyimpan logam berat pada akar dan daunnya, terutama marga Glochidion dan Phyllanthus (van der Ent et al. 2015). Beberapa jenis Phyllanthus, yaitu $P$. balgooyi Petra Hoffm. dan A. J. M. Baker, $P$. erythrotrichus C. B. Rob., P. rufuschaneyi Welzen, R.W.Bouman dan Ent, dan $P$. securinegioides Merr. berperan sebagai hiperakumulator nikel (van der Ent 2015; Bouman et al. 2018a). Glochidion littorale juga dilaporkan mampu menyimpan timbal dan kadmium dari lingkungan yang tercemar (Meepun et al. 2014). Oleh sebab itu, suatu kajian khusus mengenai potensi Phyllanthaceae sebagai 
bioakumulator logam berat pada ekosistem rawa bakau dan tambak perlu dilakukan. Hal tersebut dikarenakan tipe ekosistem ini rentan tercemar logam berat, seperti arsen, kadmium, kromium, merkuri, tembaga, timbal, dan besi (Wang et al. 2013; Maldonado-Román et al. 2016).

\section{KESIMPULAN}

Anggota suku Phyllanthaceae yang dikoleksi dari daerah sekitar rawa bakau dan tambak di Telang Asri terdiri atas 7 jenis, yaitu Glochidion littorale, G. zeylanicum, Phyllanthus amarus, P. debilis, $P$. niruri, P. reticulatus, dan $P$. virgatus. Tiga jenis di antaranya merupakan rekaman baru untuk Flora Madura, yaitu G. zeylanicum, P. amarus, dan P. debilis.

\section{DAFTAR PUSTAKA}

Airy Shaw HK. 1978. Notes on Malesian and other asiatic euphorbiaceae. Kew Bulletin 33:25-77.

Airy Shaw HK. 1981. The euphorbiaceae of Sumatra. Kew Bulletin $36: 239-374$

Airy Shaw HK. 1982. The euphorbiaceae of central malesia (Celebes, Moluccas, Lesser Sunda Is.). Kew Bulletin 37:1-40.

Amalia F, Yuliani, Indah NK. 2016. Keanekaragaman tumbuhan mangrove di Kawasan Pantai Tengket, BangkalanMadura. LenteraBio 5:20-24

APG. 2016. An update of the Angiosperm Phylogeny Group classification for the orders and families of flowering plants: APG IV. Botanical Journal of the Linnean Society 181:1-20.

Backer CA, Bakhuizen van den Brink RC Jr. 1963. Flora of Java. Vol. I. Groningen: NVP Noordhoff.

Bouman RW, van Welzen P, Sumail S, Echevarria G, Erskine PD, van der Ent A. 2018a. Phyllanthus rufuschaneyi: a new nickel hyperaccumulator from Sabah (Borneo Island) with potential for tropical agromining. Botanical Studies 59:9.

Bouman RW, Keßler PJA, Telford IRH, Bruhl JJ, van Welzen PC. 2018b. Subgeneric delimitation of the plant genus Phyllanthus (Phyllanthaceae). Blumea 63:167-198.

Challen G. 2015. Phyllanthaceae. In: Utteridge T, Bramley G (Eds.). The Kew Tropical Plant Families Identificatiom Handbook. 2nd edition. Kew: Kew Publising. p. 96-97.

Chia EJJ, Ooi ZY, Lua HK, Loo AHB, Ang WF, Ong KH, Wong KM. 2017. Glochidion obscurum B1. (Phyllanthaceae), a new record for Singapore. Nature in Singapore 10:49-53.

Giesen W, Wulffraat S, Zieren M, Scholten L. 2006. Mangrove Guidebook for Southeast Asia. Thailand: FAO and Wetlands International.

Hariri MR, Irsyam ASD. 2019. Jenis-jenis gulma pada Kebun Tebu di Kecamatan Asembagus, Situbondo, Jawa Timur: kelompok eudikotiledon. Jurnal Riset Biologi dan Aplikasinya 1:47-53.

Heijkoop M, van Welzen PC. 2017. A revision of the genus Actephila (Phyllanthaceae) in the Malesian region. Blumea 62:7-25.

Hidayah Z, Suharyo OS. 2018. Analisa perubahan penggunaan lahan wilayah pesisir Selat Madura. Rekayasa 11: 19-30.
Irsyam ASD. 2015. Kajian floristik suku Rutaceae di kawasan Madura [Thesis]. Bogor, Indonesia: IPB University.

Maldonado-Román M, Jiménez-Collazo J, Malavé-Llamas K, Musa-Wasil JC. 2016. Mangroves and their response to a heavy metal polluted wetland in the north coast of puerto rico. Journal of Tropical Life Science 6:210-218.

Meepun N, Saguansakbaramee N, Wongchuphan R. 2014. Analysis of lead and cadmium contents in local vegetables in surat thani, Thailand. Walailak Journal of Science and Technology 11:455-461.

Rifai MA. 2013a. Pemberlanjutan ketersohoran ramuan Jamu Madura (beserta catatan tentang peran yang seyogianya dimainkan oleh Universitas Trunojoyo). Dalam: Seminar Pengembangan Sumber Daya Hayati Madura sebagai Bahan Obat. Bangkalan, Indonesia.

Rifai MA. 2013b. Memadurakan Pembangunan Madura. In: Rifai MA, Purwandari U, Mutmainnah, Arif S, Dzulkarnain I (Eds.). Seserpih Garam Madura. Bangkalan:UTM Press. p. 167-188.

Rugayah, Retnowati A, Windadri FI, Hidayat A. 2004. Pengumpulan Data Taksonomi. In: Rugayah, Widjaja EA, Praptiwi (Eds.). Pedoman Pengumpulan Data Keanekaragaman Flora. Bogor:Puslit-LIPI. p. 5-42.

Setiawan E. 2016. Seratus Flora Madura Jilid 1. Bangkalan, Madura:UTM Press.

Soerjani M, Kostermans AJGH, Tjitrosoepomo G. 1987. Weeds of Rice in Indonesia. Jakarta: Balai Pustaka.

Souleymane D, Clémentine YA, Ali M, Adama B. 2018. Weeds in the vegetable Garden of The Town of Gagnoa (Côte d'Ivoire). Journal of Agriculture and Veterinary Science 11:49-59.

Supriadi S, Romadhon A, Farid A. 2015. Struktur komunitas Mangrove di Desa Martajasah Kabupaten Bangkalan. Jurnal Kelautan 8:44-51.

The Global Biodiversity Information Facility. 2019a. Phyllanthus amarus Schumach. and Thonn. in GBIF Secretariat (2019). GBIF Backbone Taxonomy. DOI:10.15468/39omei accessed via GBIF.org on 2020-02-14

The Global Biodiversity Information Facility. 2019b. Phyllanthus debilis Willd. in GBIF Secretariat (2019). GBIF Backbone Taxonomy. DOI:10.15468/39omei accessed via GBIF. org on 2020-02-14

Tomlinson PB. 2016. Family: Euphorbiaceae. In: Tomlinson PB (Eds.). The Botany of Mangroves. Cambridge: Cambridge University Press. p. 244-250.

van Balgooy MMJ. 1987. Collecting. In: de Vogel EF (Eds.). Manual of Herbarium Taxonomy Theory and Practice. Jakarta:UNESCO. p. 14-19.

van der Ent A, Erskine P, Sumail S. 2015. Ecology of nickel hyperaccumulator plants from ultramafic soils in Sabah (Malaysia). Chemoecology 25:243-259.

van Welzen PC, Chayamarit K. 2007. Flora of Thailand Vol. 8(2): Euphorbiaceae (Genera G-Z). Bangkok: The Forest Herbarium.

Verwijs JIM, Bouman RW, van Welzen PC. 2019. A taxonomic revision of Phyllanthus subgenus Macraea (Phyllanthaceae). Blumea 64:231-252.

Wang Y, Qiu Q, Xin G, Yang Z, Zheng J, Ye Z, Li S. 2013. Heavy metal contamination in a vulnerable mangrove swamp in South China. Environmental Monitoring and Assessment 185: 5775-5787.

Webster GL. 1970. A revision of Phyllanthus (Euphorbiaceae) in The Continental United States. Brittonia 22:44-76.

Yuliana E, Hewindati YT, Winata A, Djatmiko WA, Rahadiati A. 2019. Diversity and characteristics of mangrove vegetation in Pulau Rimau Protection Forest, Banyuasin District, South Sumatra, Indonesia. Biodiversitas 20:15-1221. 